\title{
The influence of direct stray current on the corrosion performance of buried oil pipeline
}

\author{
Lajun Feng, Jiaan Xiao ${ }^{\mathrm{a}}$, Feifei Huang and Bo Deng \\ School of materials and engineering, Xi'an University of Technology, 710048, Shanxi, China
}

\begin{abstract}
In order to investigate the protect effect of $\mathrm{Mg}$ sacrificial anode on the pipeline with interference of DC stray current along the length direction, we simulated field condition that Mg sacrificial anode was equipped at 4-meter intervals when Q235 pipeline (40 meters long) buried into soil with resistivity of $324 \Omega \cdot \mathrm{m}$ was subjected to $2 \sim 10 \mathrm{~V}$ DC potential. When the voltage of DC power was in a range of 2 to $10 \mathrm{~V}$, the field test showed that the potential of the part of $0-4$ meters at the positive electrode was decreased from $2.8 \mathrm{~V}$ to $0.45 \mathrm{~V}$; the potential of the part of $40-36$ meters at the negative electrode increased from $-1.75 \mathrm{~V}$ to $-0.9 \mathrm{~V}$; the potential of the part of 0 36 meters was higher than the self-corrosion potential of the Q235 steel. Thus the DC stray current accelerate the corrosion of underground equipment. The potential of $\mathrm{Mg}$ sacrificial anode near the positive electrode increased from $-1.471 \mathrm{~V}$ to $1.25 \mathrm{~V}$, which caused significantly consumption of sacrificial anode. Besides, the Mg sacrificial anode potential was higher than Q235 steel pipeline from the 4-meter to the 36-meter, so the Mg sacrificial anode cannot be used for protection to Q235 steel.
\end{abstract}

Keywords: Mg sacrificial anode; Q235 steel; electrode potential; stray current.

\section{Introduction}

In recent years, with the rapid development of high-speed trains and DC power transmission [1], an increasing number of stray current flows into the underground, leading to an increase of earth potential. A survey of a DC converter station showed that several voltages of step-voltage were tested in spite of several kilometers away [2]. Hence, substations, DC converter stations and transmission corridors should be kept away from oil pipelines to minimize the interference from stray current [3]. Due to the great change of the soil environment of transmission corridors and the uncertain value of stray current, the research of stray current corrosion of underground equipment is not thorough enough, and cannot efficiently guide designers. In regard to oil pipelines, sacrificial anode protection is widely taken as measures for corrosion protection [4]. However, there were few reports on the effect of the sacrificial anode protection on equipment under the interference of DC stray current.

In this work, Q235 steel and the soil of DC converter station situated in Weinan, Shaanxi, China was chosen as the research subject and medium, respectively. A 40-meter Q235 steel pipeline was buried into the soil to simulate the real condition. Meanwhile, 2-10V DC power was applied on the Q235 steel to simulate the DC stray current. The potential of the Q235 steel, the potential of Mg

a Corresponding author : 1067060472@qq.com 
sacrificial anodes and the current diffusion distance were tested, which we hope can provide some information for the protection of underground equipment.

\section{Experiment}

In this experiment, a trench about $0.8 \mathrm{~m}$ deep and $0.4 \mathrm{~m}$ wide was dug near the 750KVA DC converter station situated in Weinan, Shaanxi, China. A steel pipe with a diameter of $5 \mathrm{~mm}$ was buried in this trench. A test point was set every 4 meters along the steel pipe by linking a wire to the steel pipe, of which the other end was above the ground. A magnesium sacrificial anode with a diameter of $10 \mathrm{~mm}$ and a length of $100 \mathrm{~mm}$ was buried around each test point within $10 \mathrm{~mm}$. The component of the magnesium sacrificial anodes was $\mathrm{Mg}-\mathrm{Al}-\mathrm{Zn}-\mathrm{Mn}$ containing $0.5 \% \mathrm{Gd}[5]$. Epoxy resin was used to seal the junction between steel wire and magnesium sacrificial anodes. The loop was constructed by a line one meter above the ground to prevent from interference. The schematic diagram is shown in Figure 1.

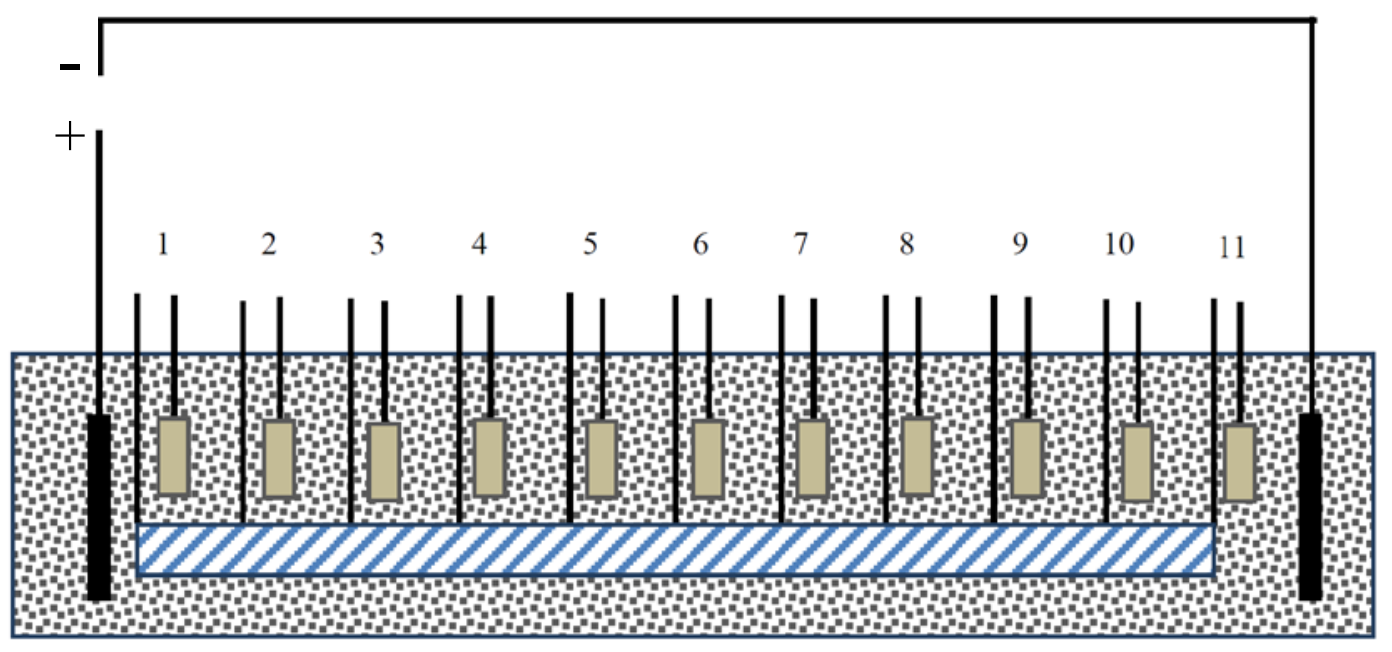

Figure 1. The schematic diagram of the experiment

The copper sulfate reference electrode (CSE) was used to measure the electrode potential [1], such as the open-circuit potential of sacrificial anode. The soil resistivity was measured using a ZC-8 Soil Resistance Tester.

\section{Measurement results and discussion}

\subsection{Soil resistivity}

Soil resistivity is one of the basic physical properties of the soil. In a certain electric field, soil resistivity can be used to illustrate the soil conductivity. The soil resistivity could preliminary judge the spread of the stray current. In this work, four-electrode method is used to test the soil resistivity [6].The schematic diagram of the test device is shown in Figure 2 and the result is shown in Table 1.

For the Table 1, the resistance of soil at different depth in Weinan is different, and the structure of soil underground is multilayered. Q235 steel with sacrificial anode protection was buried 2 meters below the ground into the soil. The distance between the poles was 2 meters. When the distance between the two test electrodes increases from $2 \mathrm{~m}$ to $8 \mathrm{~m}$, the soil resistivity measured increases from $324.05 \Omega \cdot \mathrm{m}$ to $2059.84 \Omega \cdot \mathrm{m}$. 


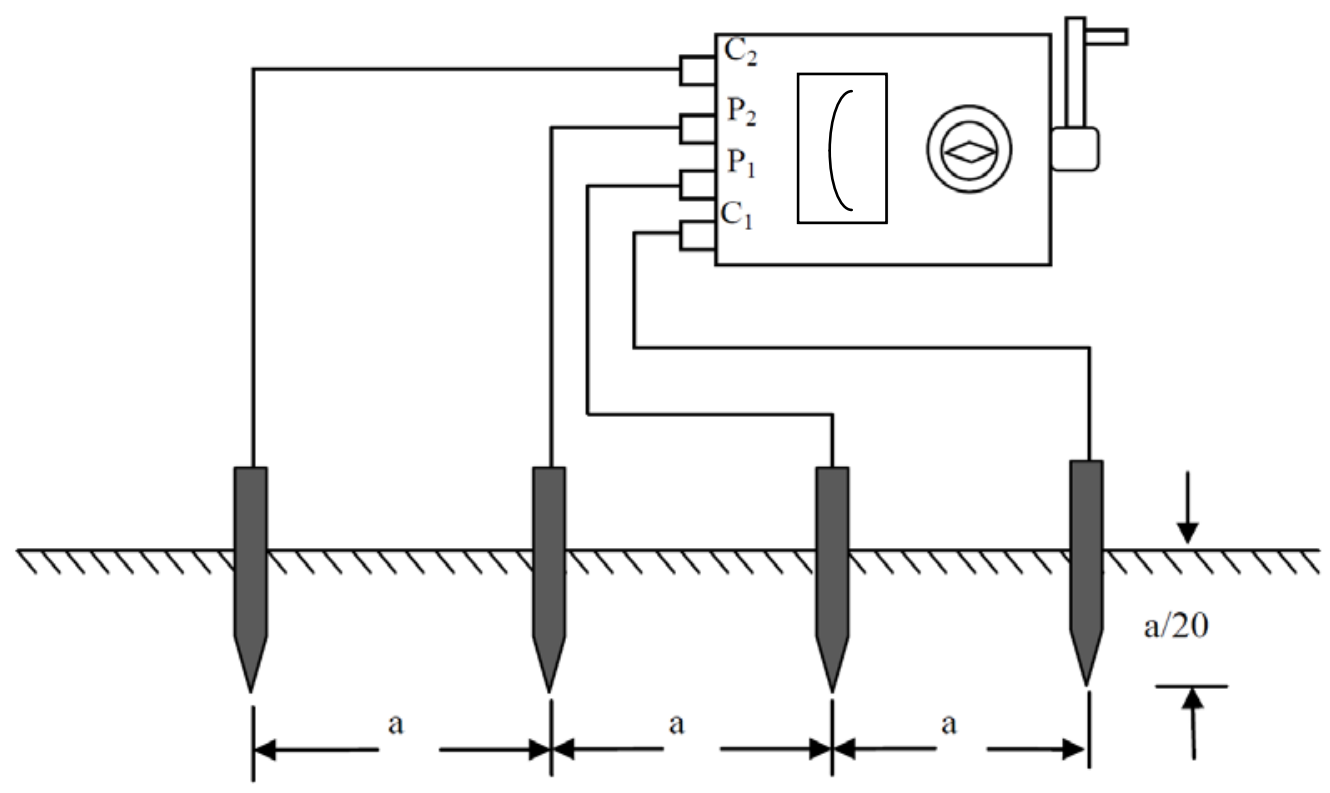

Figure 2. Schematic diagram of four electrode sounding method to measure soil resistivity

Table 1 . The measurement results of soil resistivity

\begin{tabular}{|c|c|c|c|c|}
\hline Measuring times & 2 & 4 & 6 & 8 \\
\hline 1 & 25 & 21.5 & 22.8 & 20.5 \\
\hline 2 & 26 & 21.5 & 25.2 & 20.2 \\
\hline 3 & 26.4 & 21.5 & 25.4 & 20.8 \\
\hline Average resistance $(\Omega)$ & 25.8 & 21.5 & 24.5 & 20.5 \\
\hline Average resistivity $(\Omega \cdot \mathrm{m})$ & 324.05 & 540.08 & 1230.88 & 2059.84 \\
\hline
\end{tabular}

\subsection{Test results of electrode potential}

The test result of the electrode potential is shown in Table2. When the circuit is open, there is no DC power applied on the Q235 steel wire. The potential of every test point of the steel wire is the same, the standard electrode potential based on copper sulfate was $-0.785 \mathrm{~V}$, and the potential of $\mathrm{Mg}$ sacrificial anode was $-1.471 \mathrm{~V}$. When circuit closes, the DC power applied on the Q235 steel wire, of which the voltage is $2 \mathrm{~V}$ and the current is $1.26 \mathrm{~A}$. The first test point (NO.1) is directly connected to the positive electrode of the external power source. The potential of NO.1 test point on Q235 steel wire was $2.864 \mathrm{~V}$ (CSE). The potential of NO.11 test point near the negative electrode was $-1.731 \mathrm{~V}$ (CSE). However, the potential difference between NO.1 and NO.10 was not $2 \mathrm{~V}$ but $4.595 \mathrm{~V}$, indicating that the potential of Q235 steel test points at the power input point could shifted positively and at the power output point could shifted negatively. The potential of Q235 steel between NO.1 and NO.2 near the positive electrode declines sharply from $2.864 \mathrm{~V}$ to $0.452 \mathrm{~V}$ (CSE). The potential of 
Q235 steel between NO.11 and NO.10 near the negative electrode was increased by a large margin from $-1.731 \mathrm{~V}$ to $-0.981 \mathrm{~V}$. Meanwhile, the potential between NO.3 and NO.8 test points of Q235 steel was changed slightly. When the Mg sacrificial anode was connected to Q235 steel, the potential of every test point of the Q235 steel was less than about $0.01 \mathrm{~V}$. However, the potential of $\mathrm{Mg}$ sacrificial anode had a notable change. The potential of $\mathrm{Mg}$ sacrificial anode at NO.1 test point near positive electrode was risen from $-1.471 \mathrm{~V}$ to $1.251 \mathrm{~V}$ (CSE). The potential of $\mathrm{Mg}$ sacrificial anode at NO.2 test point was increased from $-1.471 \mathrm{~V}$ to $0.226 \mathrm{~V}$ (CSE). What's more, the potential of $\mathrm{Mg}$ sacrificial anode was lower than that of Q235 steel both at NO.11 and NO.10 test points near the negative electrode. The curve is shown in Figure 3 based on the result in Table 2.

Table 2. Test results of electrode potential(V)

\begin{tabular}{|c|c|c|c|c|c|c|c|c|c|c|c|}
\hline Number & $\mathbf{1}$ & $\mathbf{2}$ & $\mathbf{3}$ & $\mathbf{4}$ & $\mathbf{5}$ & $\mathbf{6}$ & $\mathbf{7}$ & $\mathbf{8}$ & $\mathbf{9}$ & $\mathbf{1 0}$ & $\mathbf{1 1}$ \\
\hline $\begin{array}{c}\text { Open circuit potential } \\
\text { of Q235 steel }\end{array}$ & -0.786 & -0.785 & -0.784 & -0.786 & -0.785 & -0.787 & 0.785 & -0.785 & -0.786 & -0.785 & -0.784 \\
\hline $\begin{array}{c}\text { Closed circuit potential } \\
\text { of Q235 steel }\end{array}$ & 2.864 & 0.452 & 0.022 & -0.084 & -0.165 & -0.328 & -0.310 & -0.304 & -0.487 & -0.981 & -1.731 \\
\hline $\begin{array}{c}\text { Open circuit potential } \\
\text { of Mg sacrificial anode }\end{array}$ & -1.471 & -1.471 & -1.470 & -1.471 & -1.470 & -1.471 & -1.471 & -1.471 & -1.471 & -1.471 & -1.471 \\
\hline $\begin{array}{c}\text { Closed circuit potential } \\
\text { of Mg sacrificial anode }\end{array}$ & 1.251 & 0.226 & 0.071 & 0.054 & -0.103 & -0.150 & -0.188 & -0.212 & -0.414 & -1.485 & -1.736 \\
\hline
\end{tabular}

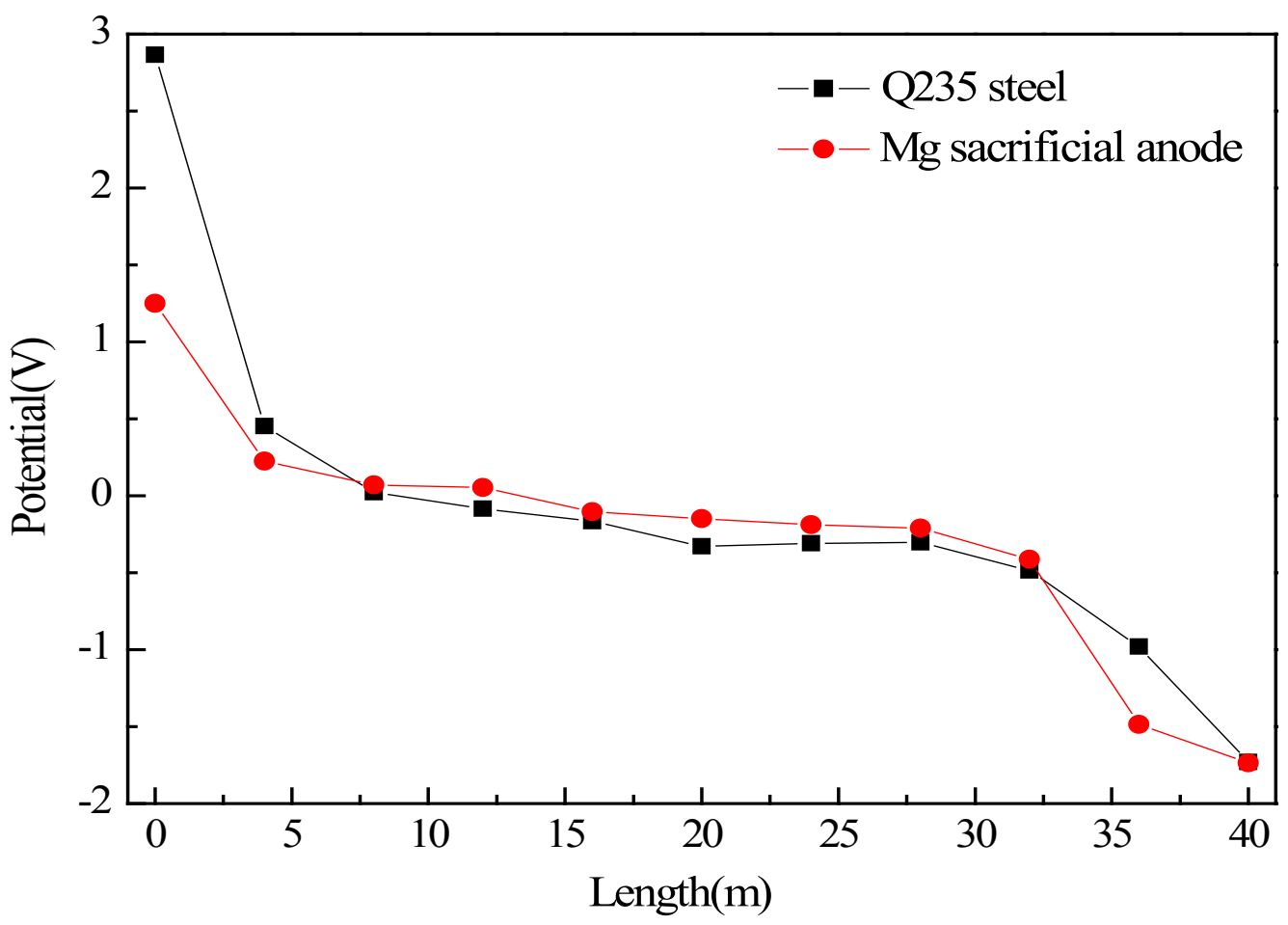

Figure 3. The electrode potential of the simulated underground pipeline

As shown in Figure 3, when the 2V DC Power was applied, the potential of most part of the 
pipelineis higher than the self-corrosion potential $-0.785 \mathrm{~V}$, except for the part 4 meters from the negative electrode, of which the potential is lower than $-0.785 \mathrm{~V}$. It is known that the increase of potential cancause Anodic Polarization, accelerating corrosion rate; the decrease of potential can cause Cathodic Polarization, decelerating corrosion rate [7]. Therefore when 2V DC power was applied on the underground pipeline, about 36 meters of the pipeline was accelerated to corrode. Meanwhile, the result shows that the potential of the pipeline had a slight changed with the increasing of voltage of the DC power from $2 \mathrm{~V}$ to $10 \mathrm{~V}$. This mainly because the discharge capacity of the soil was improved with the increasing of the potential applied, when the soil resistivity remained unchanged.

Figure 3 shows that, for the underground pipeline under the interfering of DC stray current using the protection of $\mathrm{Mg}$ sacrificial anode, the potential of $\mathrm{Mg}$ sacrificial anode was up to $1.25 \mathrm{~V}$. That is to say DC stray current can induce the increase of the sacrificial anode potential. Although the potential of the sacrificial anode in the effect of DC stray current was lower than that of Q235 steel, and higher than the self-corrosion potential of Q235 steel, which results in less protection to Q235 steel [8]. Besides, the potential of the sacrificial anode was too high, reached $1.25 \mathrm{~V}$, speeding up the magnesium depletion [9]. So, it is unreasonable in economical. The sacrificial anode potential near the negative electrode was also shifted negatively, leading to Cathodic Polarization. So the sacrificial anode has less significant effect on protection to this part of Q235 steel. In the middle part between positive and negative electrode, the potential of the sacrificial anode was slightly higher than that of Q235 steel. The main reason was that the DC stray current accelerated the corrosion of the sacrificial anode, and there is no enough time to dissolve the corrosion products attached to the $\mathrm{Mg}$ sacrificial anode surface [10], which increased the resistance of $\mathrm{Mg}$ sacrificial anode. Since the potential of the $\mathrm{Mg}$ sacrificial anode was higher than Q235 steel in the effect of stray current, the Mg sacrificial anode cannot be used for protection to Q235 steel.

\section{Conclusions}

In this work, A 40-meter Q235 steel pipeline was buried into the soil with the resistivity of $324 \Omega \cdot \mathrm{m}$ to simulate the real condition. Meanwhile, 2 10V DC power was applied on the Q235 steel, and on Mg sacrificial anodes was buried at every 4-meter along the pipeline. The field test showed that when the voltage of DC power is in a range of $2 \sim 10 \mathrm{~V}$, the potential of the Q235 steel kept stable, the positive potential was $2.8 \mathrm{~V}$, the cathode potential was $-1.75 \mathrm{~V}$. For the part 4 meters from the positive electrode, it is crucially corroded by stray current, the potential decreased from $2.8 \mathrm{~V}$ to $0.45 \mathrm{~V}$. Negative potential was reduced greatly, the self-corrosion potential of the Q235 steel was as low as $-1.75 \mathrm{~V}$. The potential of the part 4 meters from the negative electrode increased from $-1.75 \mathrm{~V}$ to $-0.9 \mathrm{~V}$. For the middle part of 36 meters, the potential of this part was higher than the self-corrosion potential of the Q235 steel. The DC stray current accelerated the corrosion of underground equipment. The potential of $\mathrm{Mg}$ sacrificial anode near the positive electrode increased from $-1.471 \mathrm{~V}$ to $1.25 \mathrm{~V}$. The potential of the sacrificial anode was too high to protective the underground equipment, because it was consumed significantly. The potential of $\mathrm{Mg}$ sacrificial anode from the 4-meter to the 36-meter is higher than that of Q235steel pipeline. So Mg sacrificial anode cannot be used for protection to Q235 steel.

\section{References}

1. Y. B. Guo, Ch. Liu, D. G. Wang, Sh. H. Liu, PETRO SCI, 12, 316-324 (2015).

2. Y. Q. Gao, J. L. He, R. Zeng, EP, 34, 1487-1492 (2001).

3. A. L. Gao, Q. J. Zhu, B. R. Hou, Sh. T. Zhang, GAS\&HEAT, 29, 6-10 (2009).

4. Y. B. Huang, X. B. Liu, H. D. Ding, G. W. Song, X.R. Chen, Q.Y. Zhang, Equipment Environmental Engineering, 7, 46-48 (2010).

5. W.X.Wu. Xi'an university of technology, (2012).

6. Q. Feng, Y. P.Zhang, H. Yu, L. Q. Yu, Y. Li, AP, 30, 123-130 (2015).

7. I. L. Rosenfeld,I. K. Marshakov, The Journal of science and Engineering, 20, 115-125 (1964). 
8. Y. H. Song, Zh. Ch. Guo, A. M. Fan, Corrosion science and protection technology, 16, 24-28 (2004).

9. Q. Feng, N. X. Xu, Journal of Chinese society corrosion and protection, 17, 106-110 (1997).

10. A.M. Simões, D. Battocchi, D.E. Tallman, G.P. Bierwagen, CORROS SCI, 49, 46-48 (2007). 